\title{
Biosorptive uptake of arsenic(V) by steam activated carbon from mung bean husk: equilibrium, kinetics, thermodynamics and modeling
}

\author{
Sandip Mondal ${ }^{1,2} \cdot$ Kaustav Aikat $^{1} \cdot{\text { Gopinath } \text { Halder }^{2}}^{2}$
}

Received: 24 February 2017/ Accepted: 18 July 2017/Published online: 28 July 2017

(C) The Author(s) 2017. This article is an open access publication

\begin{abstract}
The present investigation emphasizes on the biosorptive removal of toxic pentavalent arsenic from water using steam activated carbon prepared from mung bean husk (SAC-MBH). Characterization of the synthesized sorbent was done using different instrumental techniques, i.e., SEM, BET and point of zero charge. Sorptive uptake of $\mathrm{As}(\mathrm{V})$ over steam activated $\mathrm{MBH}$ as a function of $\mathrm{pH}$ (3-9), agitation speed (40-200 rpm), dosage (50-1000 mg) and temperature (298-313 K) was studied by batch process at arsenic concentration of $2 \mathrm{mg} \mathrm{L}^{-1}$. Lower $\mathrm{pH}$ increases the arsenic removal over the $\mathrm{pH}$ range of 3-9. Among three adsorption isotherm models examined, Langmuir model was observed to show superior results over Freundlich model. The mean sorption energy (E) estimated by Dubinin-Radushkevich model suggested that the process of adsorption was chemisorption. Thermodynamic parameters confer that the sorption process was spontaneous, exothermic and feasible in nature. The pseudo-second-order rate kinetics of arsenic gave better correlation coefficients as compared to pseudo-first-order kinetics equation. Three process parameters, viz. adsorbent dosage, agitation speed and $\mathrm{pH}$ were opted for optimizing As $(V)$ elimination using central composite design matrix of response surface methodology (RSM). The identical design setup was used for artificial neural network (ANN) for comparing its prediction capability with RSM towards
\end{abstract}

Gopinath Halder

gopinath_haldar@yahoo.co.in

1 Department of Biotechnology, National Institute of Technology, Durgapur, Durgapur 713209, India

2 Department of Chemical Engineering, National Institute of Technology, Durgapur, M. G. Avenue, Durgapur, West Bengal 713209, India
As $(\mathrm{V})$ removal. Maximum arsenic removal was observed to be $98.75 \%$ at sorbent dosage $0.75 \mathrm{gm} \mathrm{L}^{-1}, \mathrm{pH} 3.0$, agitation speed $160 \mathrm{rpm}$ and temperature $308 \mathrm{~K}$. The study concluded that SAC-MBH could be a competent adsorbent for $\mathrm{As}(\mathrm{V})$ removal and $\mathrm{ANN}$ model was better in arsenic removal predictability results than RSM model.

Keywords Biosorption - Arsenic - Mung bean husk · Thermodynamic parameters $\cdot$ RSM $\cdot$ ANN

\section{Introduction}

The presence of Arsenic (As, $Z=33$ ) in terms of most plentiful element in the human body, seawater and earth's crust is 12th, 14th and 20th position, respectively (Mandal and Suzuki 2002). As an ultra-trace nutrient, arsenic deficiency leads to inhibited growth, although beyond its necessary level it causes toxic effect on plants, animals, and human beings. Inorganic arsenics are proven to be carcinogens ( $\mathrm{Ng}$ 2005). A worldwide recognized problem related to arsenic contamination in drinking water connected with 21 countries; the largest population being risked are Bangladesh followed by West Bengal in India (Jiang et al. 2012). World Health Organization (WHO) recommended that $10 \mu \mathrm{g} \mathrm{L}^{-1}$ is the limit for utmost permissible intensity of arsenic in drinking water. Geological source such as natural reaction and volcanic emissions are the main causes of arsenic pollution where other factors such as the burning of fossil fuels, mining, smelting, and pesticide use by human activities are also responsible for arsenic toxicity (Bissen and Frimmel 2003).

Till date, several methods have been attempted such as coagulation/precipitation (Song et al. 2006), coagulation/filtration (Wickramasinghe et al. 2004), adsorption 
(Asadullah et al. 2014), oxidation (Borho and Wilderer 1996), ion exchange (Urbano et al. 2012), membrane/reverse osmosis (Fogarassy et al. 2009), and electro-coagulation (Hansen et al. 2007) to eliminate arsenic from water. Among these technologies, adsorption is preferably a good choice due to its operational easiness, cost effectiveness, eco-friendly nature and accessibility of various types of adsorbent (Ranjan et al. 2009).

For the last couple of decades, activated carbons as an adsorbent has been widely used for arsenic removal from water (Kalderis et al. 2008; Mohan and Pittman 2007; Mondal et al. 2008) as it possesses significant surface area with micro/mesopore structure along with extensive adsorption capacity. Commercial activated carbons are expensive and it is the main drawback of using this adsorbent in all the application sectors (Roy et al. 2013). Recently, some of the low cost compounds such as zirconium oxide-coated marine sand, chir pine sawdust, bagasse fly ash, clay and magnetic chitosan-bamboo sawdust composites were employed while some of the biomasses were also used to remove arsenic from water (Khan and Sing 2010; 2013, 2014, Khan and Nazir 2015; Ali et al. 2014). Chemical activated carbon (linseed cake activated carbon and waste tyre activated carbon) was also used to eliminate arsenic from aqueous solutions (Khan et al. 2016, 2017). Here, in this paper we have tried to prepare a low cost agricultural residues mung bean husk as a precursor to prepare potential carbonized adsorbent that can deal with waste disposal problem as well as the possibility of recycling the waste towards its application in removal of toxic contaminant from aqueous solution (Budinova et al. 2009; Mondal et al. 2016a, c). Vigna radiate (Mung bean) seeds are an inhabitant from the Indian subcontinent and $90 \%$ of world's mung bean is produced in Asia, and India is the top producer of this crop (Mondal et al. 2015, 2016b).

The typical optimization of a removal process requires changing one variable while fixing the other variables at a certain level. This sort of optimization process is impractical as it requires a large number of experiments to be performed due to the possibility of different factorial combinations of the test variables (Chang et al. 2011). This sort of problem can be overcome by using appropriate optimization process like RSM and ANN.

The aims of the present study includes: (1) synthesis of steam activated mung bean carbon as an adsorbent (2) characterization of adsorbent material, (3) investigation of the effects of process parameters such as adsorbate solution $\mathrm{pH}$, temperature, adsorbent dosage and speed of agitation on the adsorption of $\mathrm{As}(\mathrm{V})$ onto adsorbents, (4) Isotherm, kinetics and thermodynamics of the adsorption process and (5) finding an optimum condition of adsorption process using RSM and ANN and their comparison.

\section{Materials and methods}

\section{Preparation of adsorbate solution}

Sodium arsenate dibasic heptahydrate $\left(\mathrm{Na}_{2} \mathrm{HAsO}_{4} \cdot 7 \mathrm{H}_{2} \mathrm{O}\right)$ as arsenic sourced compound was purchased from Fisher scientific (USA) and was dissolved in deionized water $(18.2 \mathrm{M} \Omega)$ to prepare adsorbate solution. Arsenic stock solution of $3 \mathrm{ppm}$ equivalent was prepared and further diluted to the desired concentration with deionised water (Millipore Corp., USA). The adsorbate $\mathrm{pH}$ was adjusted using $0.1 \mathrm{~N} \mathrm{NaOH}$ and $0.1 \mathrm{~N} \mathrm{HCl}$.

\section{Preparation of sorbents and its characterization}

The precursor mung bean husk used for preparation of activated carbon was purchased from Durgapur (India) local market. Distilled water was used to wash MBH several times followed by drying to obtain the desired precursor. In the first step of operation in a stainless steel cylindrical shelled furnace chamber, the precursor was gradually carbonized with the rate of heating of $55^{\circ} \mathrm{C}$ per $15 \mathrm{~min}$ at $550{ }^{\circ} \mathrm{C}$ for $1 \mathrm{~h}$. After carbonization, temperature was heated up to $650{ }^{\circ} \mathrm{C}$ into the furnace chamber and superheated steam was introduced at a pressure of $1.5-2.0 \mathrm{~kg} \mathrm{~cm}^{-2}$ for $1 \mathrm{~h}$ for activation of carbon (Mondal et al. 2015). The prepared activated carbon was then placed to desiccators to cool down to room temperature. Characterization of the sorbent was done properly using different instrumental techniques such as SEM, BET, FTIR and point of zero charge.

\section{Batch mode adsorption studies}

The appropriate quantity of mung bean husk derived activated carbon for the adsorption of arsenic was estimated by the batch equilibrium study. Arsenic concentration of $2 \mathrm{mg} \mathrm{L}^{-1}$ was taken in a fixed volume $(100 \mathrm{ml})$ of liquid sample in all the tested batch sorption experiments in an incubator shaker (Model Innova 42, New Brunswick Scientific, Canada) at $310 \mathrm{~K}$. Process optimization was done by altering the dosage ( $50 \mathrm{mg}-1 \mathrm{~g}$ ), $\mathrm{pH}(3-9)$ and agitation speed (40-180) for a preset contact time interval. The concentration of arsenic in a flask was measured by taking adsorbate solution at a specific time interval. Arsenic solution from flask was taken at a specific time interval and then centrifuged at $4000 \mathrm{rpm}$ for $20 \mathrm{~min}$. Supernatant solution collected at different time interval was analyzed for the presence of arsenic using arsenic kit (Merck, USA). Each batch experiment was conducted in triplicate and for data analysis purposes mean values were used. At equilibrium $q_{\mathrm{e}}\left(\mathrm{mg} \mathrm{g}^{-1}\right)$ conditions, the quantity of arsenic 
compound adsorbed can be estimated according to the mass balance from the initial and final equilibrium concentrations by means of the following equation:

$q_{\mathrm{e}}=\frac{\left(C_{\mathrm{i}}-C_{\mathrm{e}}\right) V}{m}$,

where $C_{\mathrm{i}}$ is the initial arsenic concentration $\left(\mathrm{mg} \mathrm{L}^{-1}\right)$, $C_{\mathrm{e}}$ is the equilibrium arsenic concentration $\left(\mathrm{mg} \mathrm{L}^{-1}\right), V$ is the volume of the arsenic solution (L) in contact with the adsorbent, $m$ is the mass of the adsorbent (g).

The percent removal of arsenic was calculated using the following relation:

$\operatorname{Sorption}(\%)=\frac{\left(C_{\mathrm{i}}-C_{\mathrm{e}}\right)}{C_{\mathrm{i}}} \times 100$.

Control experiments were conducted in each batch study to confirm that arsenic was not adsorbed by the flask wall.

\section{Models for kinetic and equilibrium studies}

The evaluation of the adsorption kinetics was tested by subsequent models, which are pseudo-first order (Kumar et al. 2003), pseudo-second order (Ho et al. 2000) and Elovich (Chien and Clayton 1980).

The assessment of the equilibrium adsorption isotherm was checked by different models. These are: Langmuir (Mohan et al. 2011a), Freundlich (Mohan et al. 2011a), Temkin and Dubinin-Radushkevich (Dubinin 1960).

\section{Removal process modeling}

The optimization of $\mathrm{As}(\mathrm{V})$ elimination from water was done through RSM by the same process variables used in batch mode, viz. adsorbent dosage, $\mathrm{pH}$ and agitation speed. Concentration of $\mathrm{As}(\mathrm{V})$ was taken $2 \mathrm{mg} \mathrm{L}^{-1}$ in this modeling process. CCD was chosen from RSM to form experimental matrix to build up a suitable model for explaining the process of arsenic removal. Table 1 shows the variables range and levels used in this experiment. This modeling process had taken removal percentage of arsenic as the response of the system.

Quadratic equation to correlate response function and variables process can be mathematically done by the following equation:

$x_{j} \quad \gamma=\beta_{0}+\sum_{i=1}^{k} \beta_{i} x_{i}+\sum_{i=1}^{k} \beta_{i i} x_{i}^{2}+\sum_{i=1} \sum_{j=1+1} \beta_{i j} x_{i} x_{j}+\varepsilon$,

where $\beta_{0}$ is the constant coefficient, $\beta_{i}, \beta_{i i}$ and $\beta_{i j}$ are linear, quadratic and interaction coefficients effect, respectively, $x_{i}, x_{j}$ are independent variables and $\varepsilon$ is the error.
In $\mathrm{CCD}$, three-dimensional response plots were generated that explain the interactive effect of independent variables with their corresponding effect.

Artificial neural network model works in a very complicated manner like the neurons of the nervous system of human to make a refined optimal decision based on the data or stimuli. Currently for engineering application, so many ANN models have been developed such as feed forward, multilayer perception (MLP), and radial basis function. The present investigation studied $\mathrm{As}(\mathrm{V})$ removal modeling using feed-forward three-layer back propagation algorithm with a linear transfer function.

ANN model essentially consists of three layers, i.e., input layers, hidden layers and an output layer. The independent variables are input and hidden layers, while dependent variables are output layer. ANN model is structured in such a fashion that all layers are interconnected by a processing unit called neuron, while the neurons are connected to each other by links (Fig. 1). Input layer takes the information from outer source and pass the information to the next layer (hidden) for processing of data. Input values were weighted individually before it passes through the hidden layer. The hidden layer processes the data and analyzes to produce the output based on the sum of the weighted input values (Khataee and Khani 2009). The mathematical equation to denote the net input $Y_{i j}$ of the neuron $j$ in the layer $i$ is represented by

$Y_{i j}=\sum_{k=1}^{n_{i-1}} W_{i j k} V_{i-1, k}+\theta_{i j}$,

$V_{i j}=g\left(Y_{i j}\right)$,

where $V_{i k}$ is the input of neuron, $W_{i j k}$ is the weight of connection and $\theta_{i j}$ is the bias of neuron. The neuron output $V_{i j}$ is estimated using an activation function $g\left(Y_{i j}\right)$. Equations (4) and (5) can be used to model nonlinear relationships between a set of input and output variables. It has to be noted that the training is performed using the input as well as output data taken from the system under study.

In this present study, same input, viz. adsorbent dosage, $\mathrm{pH}$ and agitation was taken from RSM to model the ANN process. CCD matrix generated from RSM along with the output results was used in ANN modeling to train output and input layer. Matlab (version 7.12) toolbox of Neural Network was used to calculate the ANN data.

\section{Results and discussion}

\section{Characterization of activated carbon}

The BET-specific surface area and micro-pore volume were estimated to be $405 \mathrm{~m}^{2} \mathrm{~g}^{-1}$ and $0.2853 \mathrm{~cm}^{3} \mathrm{~g}^{-1}$, 
Table 1 CCD with experimental and predicted values

\begin{tabular}{|c|c|c|c|c|c|c|c|c|c|}
\hline \multirow{2}{*}{\multicolumn{2}{|c|}{ Variable }} & \multirow[t]{2}{*}{ Unit } & \multicolumn{2}{|r|}{ Symbols } & \multicolumn{5}{|l|}{ Range } \\
\hline & & & & & $-\alpha$ & -1 & 0 & 1 & $+\alpha$ \\
\hline \multicolumn{2}{|l|}{$\mathrm{pH}$} & & & $A$ & 1.295 & 3 & 5.5 & 8 & 9.704 \\
\hline \multicolumn{2}{|c|}{ Agitation speed } & $\mathrm{rpm}$ & & $B$ & 45.683 & 90 & 155 & 220 & 264.31 \\
\hline \multicolumn{2}{|c|}{ Dosage } & $\mathrm{mg}$ & & C & 127.28 & 400 & 800 & 1200 & 1472.72 \\
\hline & $A$ & $B$ & $C$ & $A$ & $B$ & $C$ & Observed & RSM & ANN \\
\hline 1 & 0 & 0 & 0 & 5.5 & 155 & 800 & 95 & 94.85 & 94.79 \\
\hline 2 & 0 & 0 & $+\alpha$ & 5.5 & 155 & 1472.71 & 87.5 & 86.76 & 87.51 \\
\hline 3 & 0 & 0 & 0 & 5.5 & 155 & 800 & 95 & 94.85 & 94.795 \\
\hline 4 & 0 & 0 & 0 & 5.5 & 155 & 800 & 94 & 94.85 & 94.795 \\
\hline 5 & -1 & 1 & 1 & 3 & 220 & 1200 & 91 & 91.58 & 90.97 \\
\hline 6 & $+\alpha$ & 0 & 0 & 9.70 & 155 & 800 & 87.5 & 87.65 & 87.749 \\
\hline 7 & 1 & 1 & -1 & 8 & 220 & 400 & 84 & 83.84 & 83.974 \\
\hline 8 & 0 & 0 & 0 & 5.5 & 155 & 800 & 95 & 94.85 & 94.795 \\
\hline 9 & 1 & -1 & 1 & 8 & 90 & 1200 & 87 & 86.98 & 86.981 \\
\hline 10 & $-\alpha$ & 0 & 0 & 1.29 & 155 & 800 & 95 & 94.2 & 94.999 \\
\hline 11 & 0 & 0 & 0 & 5.5 & 155 & 800 & 95 & 94.85 & 94.795 \\
\hline 12 & -1 & 1 & -1 & 3 & 220 & 400 & 90 & 90.48 & 90.019 \\
\hline 13 & 1 & 1 & 1 & 8 & 220 & 1200 & 87.5 & 87.93 & 87.504 \\
\hline 14 & 0 & $-\alpha$ & 0 & 5.5 & 45.68 & 800 & 87.5 & 87.41 & 87.485 \\
\hline 15 & -1 & -1 & 1 & 3 & 90 & 1200 & 87.5 & 88.13 & 87.512 \\
\hline 16 & 0 & 0 & 0 & 5.5 & 155 & 800 & 95 & 94.85 & 94.795 \\
\hline 17 & -1 & -1 & -1 & 3 & 90 & 400 & 89 & 89.03 & 89.098 \\
\hline 18 & 0 & 0 & $-\alpha$ & 5.5 & 155 & 127.28 & 84 & 84.08 & 83.997 \\
\hline 19 & 1 & -1 & -1 & 8 & 90 & 400 & 85 & 84.88 & 84.907 \\
\hline 20 & 0 & $+\alpha$ & 0 & 5.5 & 264.31 & 800 & 90 & 89.43 & 90.004 \\
\hline
\end{tabular}

respectively. Adsorbents surface charge can be estimated by the help of point of zero charge $\left(\mathrm{pH}_{\mathrm{pzc}}\right)$ and experimentally it was observed to be 8.6. FTIR spectrum of SAC$\mathrm{MBH}$ and SAC-MBH along with adsorbed As(V) molecule was shown in Fig. 2a, b, respectively. The process of adsorption has been influenced by the presence of functional groups such as carboxyl, hydroxyl, sulfate, and amino groups on the surface of an adsorbent. The SACMBH exhibited different bands at $770 \mathrm{~cm}^{-1}(\mathrm{C}-\mathrm{H}$ bend), $1068 \mathrm{~cm}^{-1}$ (C-N stretch), $1215 \mathrm{~cm}^{-1}$ (C-H bend) and $1384 \mathrm{~cm}^{-1}$ (nitro group). Sifting of some bands such as $770.39-769.25 \mathrm{~cm}^{-1}, \quad 1637.6-1629.22 \mathrm{~cm}^{-1}$ and 3393.85-3390.59 $\mathrm{cm}^{-1}$ suggests that $\mathrm{C}-\mathrm{H}$ bend, $\mathrm{N}-\mathrm{H}$ bend stretch and $\mathrm{N}-\mathrm{H}$ stretch may be participating for the adsorption of arsenic onto SAC-MBH.

One of the vital parameters in the process of adsorption is specific surface area of adsorbent, and pore size is helpful to know adsorbates binding chances with the functional group into the activated carbon. The surface structure of the raw activated carbon was found to be porous, irregular and uneven shaped where porous structure was highly heterogeneous in nature associating with high surface area in SEM micrograph as depicted in Fig. 3a. It was shown from the Fig. 3b that the pores number was reduced, and the heterogeneous structure helps to capture the $\mathrm{As}(\mathrm{V})$ molecule inside the activated carbon surface to facilitate absorption. The surface texture became smooth due to filling up of the pores by $\mathrm{As}(\mathrm{V})$ molecule adsorption. The point of zero charge of the adsorbent was estimated to be 8.6 that point out the ' $\mathrm{H}$ ' category of carbon. $\mathrm{H}$ category carbons have a lesser density of oxygencontaining functional group, more hydrophobic and showing strong acid adsorption capacity (Mohan et al. 2011b).

\section{Effect of adsorbent dosage}

Experimental results suggest that the percentage removal of the As(V) species increased (Fig. 4a) with increased dosages of adsorbent (0.5-0.75 g). Increase in adsorbent dosage means the availability of more surface area which, in turn, indicates the presence of more active binding sites 
Fig. 1 Topology of the ANN architecture

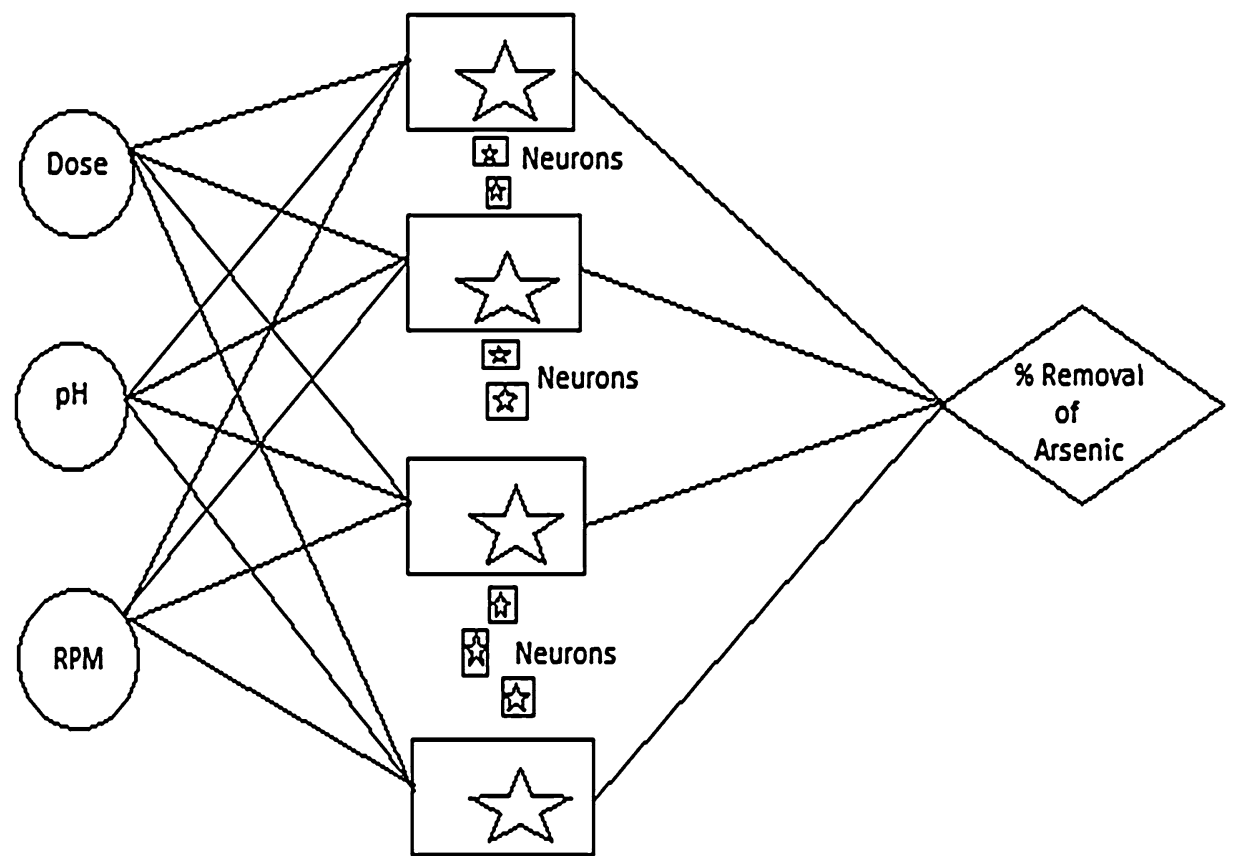

Input layers

to adsorb the adsorbate molecules (Lewinsky 2007). Further increase in dosages beyond $0.75 \mathrm{~g}$ mass did not cause any significant increment in the elimination tendency of $\mathrm{As}(\mathrm{V})$. This is due to the adsorption of almost all $\mathrm{As}(\mathrm{V})$ onto the adsorbent surface and attaining of equilibrium between the $\mathrm{As}(\mathrm{V})$ adsorbed to the adsorbent and those As(V) left in the solution. The results of this study are the following similar type of pattern reported as findings by other researchers ( $\mathrm{Li}$ et al. 2012; Roy et al. 2013). The optimum value of adsorbent dosage was $0.75 \mathrm{~g} \mathrm{~L}^{-1}$ and for the rest of the experiment this value was used.

\section{Effect of solution $\mathrm{pH}$}

The solution $\mathrm{pH}$ is a significant factor for wastewater treatment process. Figure $4 \mathrm{~b}$ presents the activated carbon behavior over the $\mathrm{pH}$ range of 3-9 and it is easily understood that the optimum arsenic elimination is achieved at $\mathrm{pH} 3$.

The solution $\mathrm{pH}$ affects the activated carbon by dissociating the functional groups on the adsorbent surface active site by changing the surface charge (pHpzc) of the activated carbon. On the other hand, the solution $\mathrm{pH}$ affects the target pollutant by changing degree of ionization ( $\mathrm{pKa}$ ) and speciation of the arsenic. Since the pHpzc of SAC$\mathrm{MBH}$ surface was 8.6, below the pHpzc value the adsorbent surface becomes positive in a solution. On the other side, $\mathrm{As}(\mathrm{V})$ has dissociation constant $\mathrm{pKa}=6.94$, thereby at $\mathrm{pH}>6.97$ it is protonated where at $\mathrm{pH}<6.97$ it is
Hidden layers

Output layer

deprotonated. Thus, it can be said that at less than $\mathrm{pH} 6.97$, $\mathrm{As}(\mathrm{V})$ remains in solution in anionic form $\left(\mathrm{H}_{2} \mathrm{AsO}_{4}{ }^{-}\right)$, so at this stage arsenate becomes negatively charged while SAC-MBH becomes positively charged, so electrostatic attraction occurs and this was most likely the adsorption mechanism (Liu et al. 2012). As the pH increases, adsorbent surface becomes less positive $(\mathrm{pH}<\mathrm{pHpzc}$ ) or more negative $(\mathrm{pH}>\mathrm{pHpzc})$. These two factors cumulatively decrease electrostatic attraction while increasing repulsion that leads to decrease in $\mathrm{As}(\mathrm{V})$ removal at higher $\mathrm{pH}$.

\section{Effect of agitation speed}

Agitation speed is a significant parameter for $\mathrm{As}(\mathrm{V})$ removal by SAC-MBH. The adsorption study was carried out at variable agitation speed ranging from 40 to $200 \mathrm{rpm}$ that has been depicted in Fig. 4c. Increasing agitation speed causes increased removal of $\mathrm{As}(\mathrm{V})$ and reached a maximum removal value at $160 \mathrm{rpm}(95 \%)$. This optimum agitation speed confirms usability of all the surface active sites of adsorbent to uptake arsenic. It was an optimum speed of agitation to assure the availability of all the surface binding sites for arsenic uptake. During slow agitation speed, SAC-MBH did not spread in the solution properly, instead it conglomerated in the solution; thus, beneath the apex layers of adsorbent it hide many active sites so apex layer is only available for adsorption and in this process hidden layers are not present to participate in the adsorption process, since they had no proper contact with As(V). 
Fig. 2 a Before and $\mathbf{b}$ after adsorption of $\mathrm{As}(\mathrm{V})$ onto SACMBH
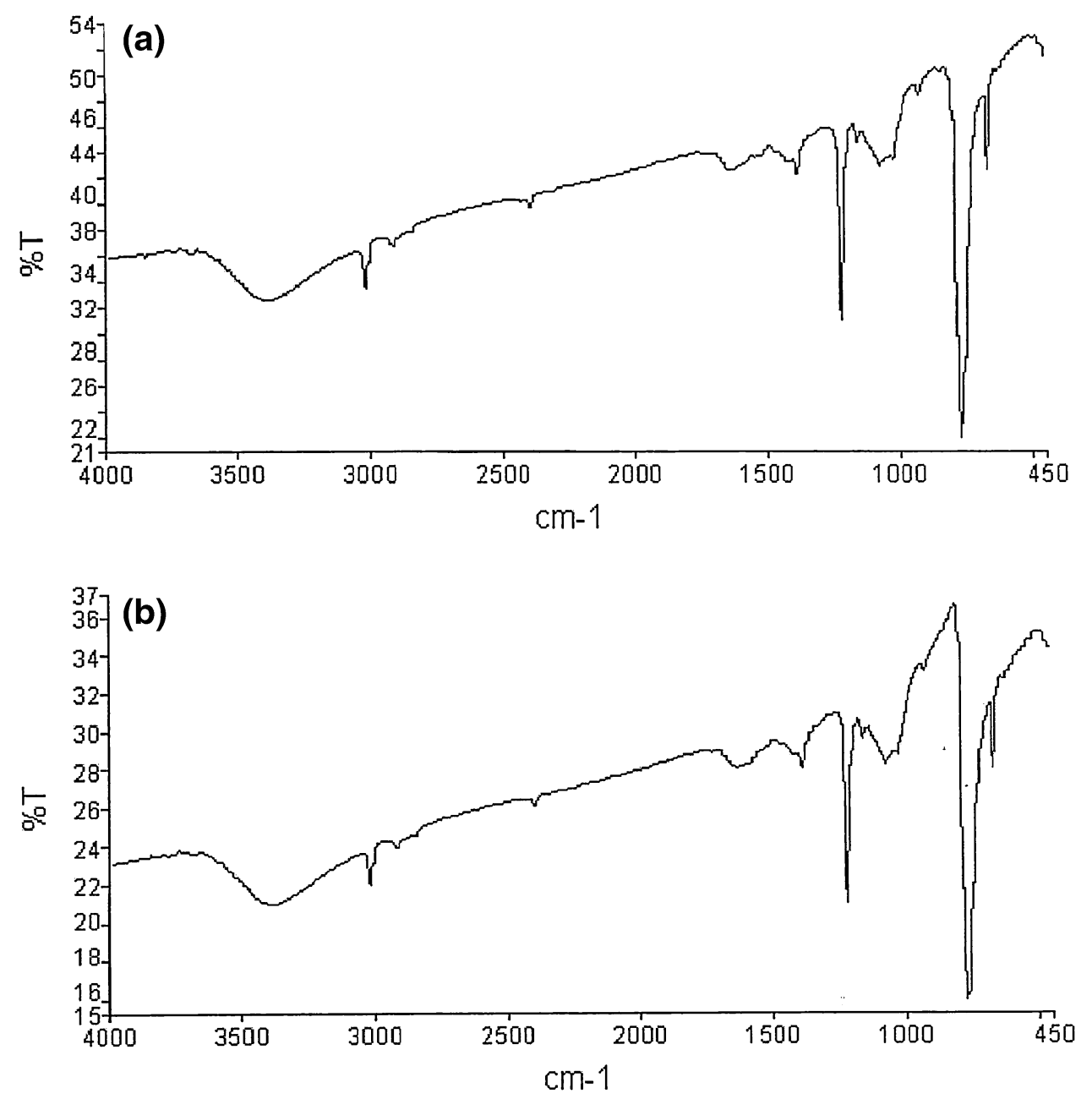
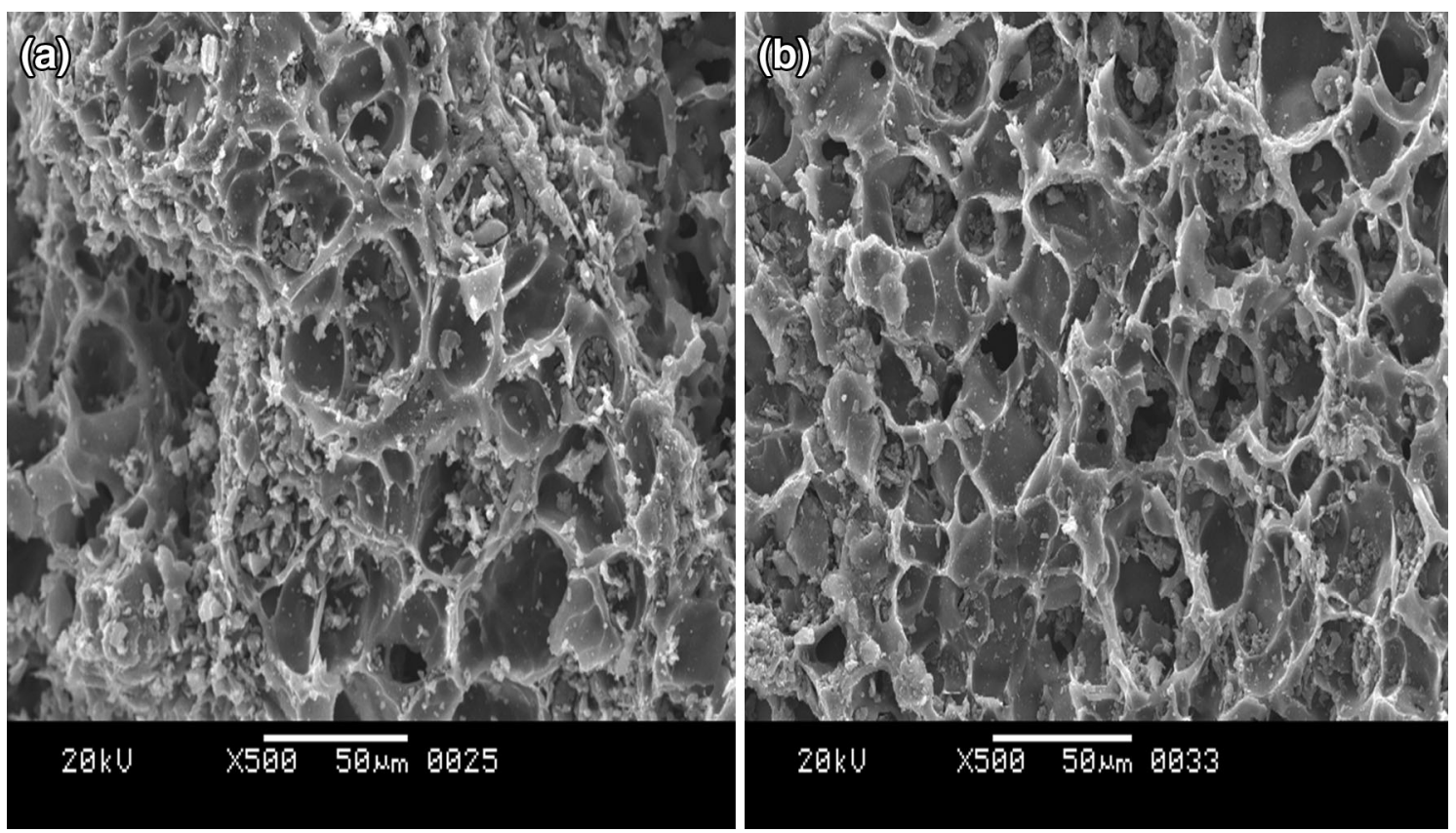

Fig. 3 a Before and $\mathbf{b}$ after adsorption of $A s(V)$ onto the surface of SAB-MBH on SEM at $\times 500$ magnification 

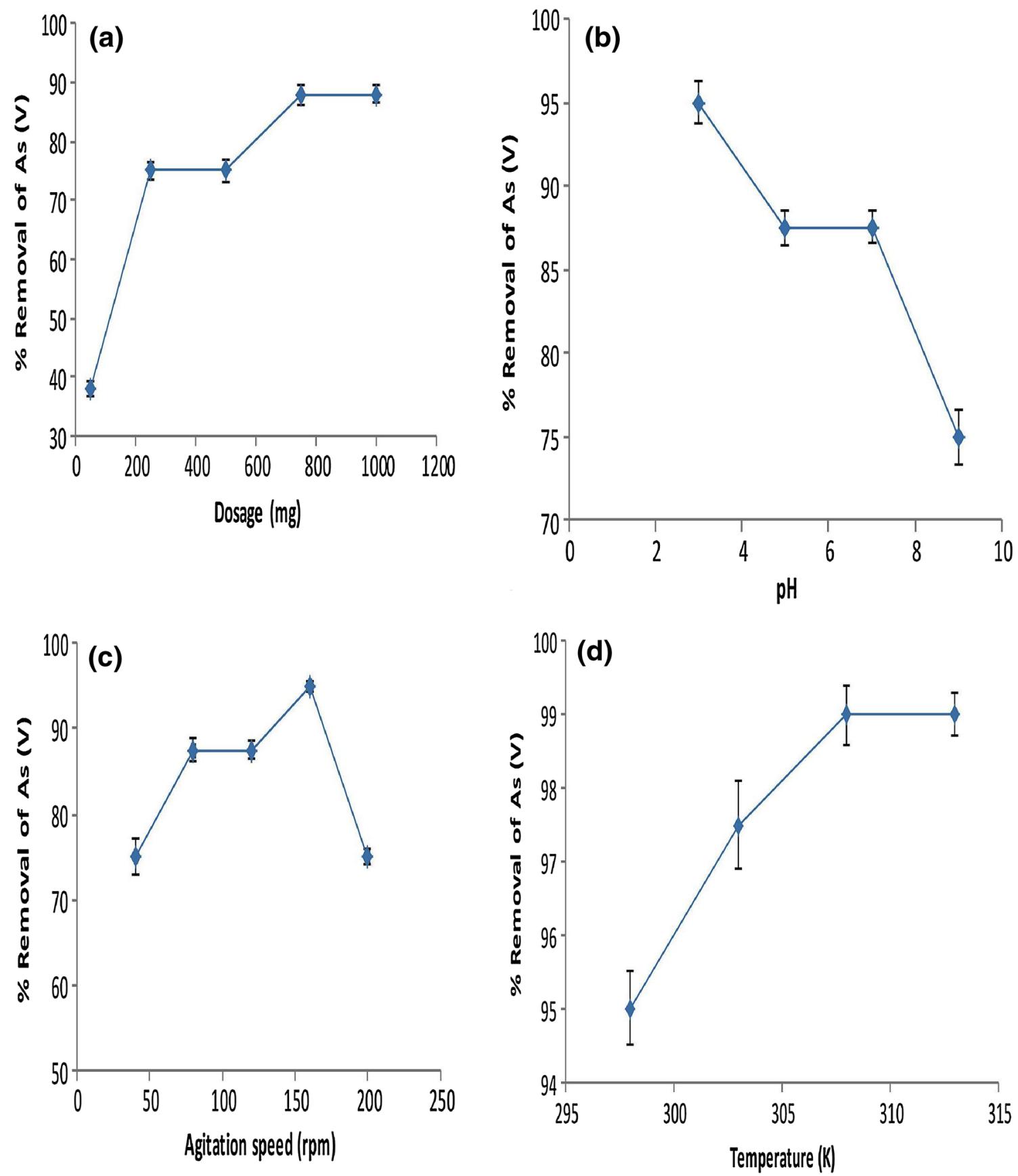

Fig. 4 Effect of a adsorbent dosage, $\mathbf{b}$ pH, $\mathbf{c}$ agitation speed, and $\mathbf{d}$ temperature on the adsorption of As(V) by SAB-MBH

In case of higher agitation speed, $\mathrm{As}(\mathrm{V})$ particles have not enough time to make a bond with SAC-MBH due to random collisions among the participant particle. Similar type of agitation speed pattern was also found by the other researchers (Liu et al. 2012; Shafique et al. 2012).

\section{Effect of temperature}

In general, the adsorption process is affected by the temperature. Influence of temperature on the arsenic adsorption by the sorbent was investigated at four different temperatures $(298,303,308$ and $313 \mathrm{~K})$.

$\mathrm{As}(\mathrm{V})$ removal was observed to increase from 95 to 98.75\% with increase in temperature as depicted in Fig. 4d. It indicates that $\mathrm{As}(\mathrm{V})$ removal by adsorption onto SAC$\mathrm{MBH}$ was encouraging at elevated temperatures. Since by further increasing the temperature the percentage removal of the adsorbate remained constant. Increasing temperature speed up the As(V) molecule while slower the retarding forces on the molecules; thereby, percentage removal of 
the sorption capacity of the adsorbent had been enhanced. Percentage removal of arsenic molecule was also increased due to pore size changes and increase in kinetic energy of the adsorbents. This type of trend was found by other authors (Pokhrel and Viraraghavan 2008).

\section{Kinetic studies}

In the process of adsorption, kinetics was done to understand two important factors: one is equilibrium time and other is adsorption mechanism. To study the mechanism of arsenic adsorption, three kinetic models were fitted. The kinetic parameters of the fitted model are presented in Table 2.

Adsorption kinetics of arsenic was investigated in the present investigation using three models, namely Lagergren pseudo-first order, pseudo-second-order and Elovich equation. Fitting and evaluation of the three models into the adsorption kinetics study ultimately give the finest model to explain the adsorption mechanism at different temperature.

\section{Theory of kinetics}

Lagergren pseudo-first-order kinetics and second-order kinetics models are mathematically explain in their linear form by the following Eqs. (6) and (7), respectively:

$\log \left(q_{\mathrm{e}}-q_{t}\right)=\log q_{\mathrm{e}}-\frac{k 1}{2.303} t$,

$\frac{t}{q_{t}}=\frac{1}{k_{2} q_{\mathrm{e}}^{2}}+\frac{1}{q_{\mathrm{e}}} t$,

where $q_{\mathrm{e}}$ and $q_{\mathrm{t}}$ are the quantity of arsenic adsorption at an equilibrium and time $t\left(\mathrm{mg} \mathrm{g}^{-1}\right) ; k_{1}\left(\min ^{-1}\right)$ and $k_{2}$ $\left(\mathrm{g} \mathrm{mg}^{-1} \mathrm{~min}^{-1}\right)$ are the pseudo first order and pseudo second order rate constants, respectively.

Table 2 Kinetic parameters for As(V) removal using activated $\mathrm{MBH}$ carbon

\begin{tabular}{lrrrr}
\hline$T(\mathrm{~K})$ & $298 \mathrm{~K}$ & $303 \mathrm{~K}$ & $308 \mathrm{~K}$ & $313 \mathrm{~K}$ \\
\hline$q_{\exp }\left(\mathrm{mg} \mathrm{g}^{-1}\right)$ & 0.253 & 0.26 & 0.253 & 0.263 \\
Pseudo-second order & & & & \\
$\quad K_{1}\left(\mathrm{~min}^{-1}\right)$ & 0.395 & 0.510 & 1.575 & 1.575 \\
$q_{\text {cal }}\left(\mathrm{mg} \mathrm{g}^{-1}\right)$ & 0.272 & 0.283 & 0.272 & 0.283 \\
$R^{2}$ & 0.989 & 0.995 & 0.999 & 0.999 \\
Elovich equation & & & & \\
$\quad a\left(\mathrm{mg} \mathrm{g}^{-1} \mathrm{~min}^{-1}\right)$ & 0.365 & 0.537 & 305.182 & 305.182 \\
$\quad b\left(\mathrm{~g} \mathrm{mg}^{-1}\right)$ & 26.315 & 27.027 & 52.631 & 52.631 \\
$R^{2}$ & 0.834 & 0.930 & 0.931 & 0.931 \\
\hline
\end{tabular}

Experimental conditions: adsorbent dosage $0.75 \mathrm{~g} ; \mathrm{pH} \mathrm{3}$, agitation speed $160 \mathrm{rpm}$; temperature $308 \mathrm{~K}$
The linear plot of $\log \left(q_{\mathrm{e}}-q_{\mathrm{t}}\right)$ versus $t$ and $t / q_{t}$ versus $t$ gives model applicability of pseudo first order and pseudo second order kinetics (Fig. 5a), respectively. The kinetic parameters $k_{1}\left(\min ^{-1}\right)$ and $k 2\left(\mathrm{~g} \mathrm{mg}^{-1} \min ^{-1}\right)$ were obtained from the slope and intercept of the above-mentioned linear plot by applying Eqs. (4) and (5).

Elovich kinetic model assumes that the active sites present on the solid surface are heterogeneous in nature and have different activation energy for chemisorptions. Generally, this model is one of the most practical to understand chemisorptions process.

The following mathematical equation helps to understand the model

$q_{t}=\frac{1}{\beta} \ln (\alpha \beta)+\frac{1}{\beta} \ln t$

where $\alpha$ is the initial sorption rate constant $\left(\mathrm{mg} \mathrm{g}^{-1} \mathrm{~min}^{-1}\right)$ and $\beta$ is the desorption constant $\left(\mathrm{g} \mathrm{mg}^{-1}\right)$. The linear plot of $q_{t}$ versus $\ln t$ gives the slope and intercept, from where the value of the parameters $\alpha$ and $\beta$ is obtained. The value of $1 / \beta$ indicates the sites available for adsorption.

\section{Prediction of best kinetic model for As(V) adsorption}

The suitability of the kinetics model was judged by their correlation coefficients $\left(R^{2}\right)$ which has been tabulated in Table 2. At first, the experimental equilibrium data were analyzed by pseudo-first-order equation. The experimental data were found to be very unfavorable for first-order kinetic model to all temperatures (Figure not shown). Therefore, it was not justifiable to use the model of $\operatorname{As}(V)$ kinetics to superheated steam activated carbon.

The experimental data were then fitted into pseudosecond-order equation. The correlation coefficients value was found to be close to unity or unity where the calculated $q_{\mathrm{e}}$ values were close to experimental $q_{\mathrm{e}}$ values at all temperature tested in this experiment. Therefore, the excellent fit of the data in the model as well as the kinetic parameters suggests that $\mathrm{As}(\mathrm{V})$ adsorption kinetics followed pseudosecond-order kinetics.

Using last experimental data, Elovich equation model was verified. The correlation coefficient did not show good linearity but the constant $\alpha$ and $\beta$ increase with increasing temperature; thus, it can be said that both the rate of chemisorptions and availability of adsorption surface would increase.

\section{Equilibrium studies}

The equilibrium adsorptive studies were done by applying different adsorption isotherm to find the relationship between the adsorption of adsorbate by adsorbent and remaining adsorbate concentration in the solution. The 

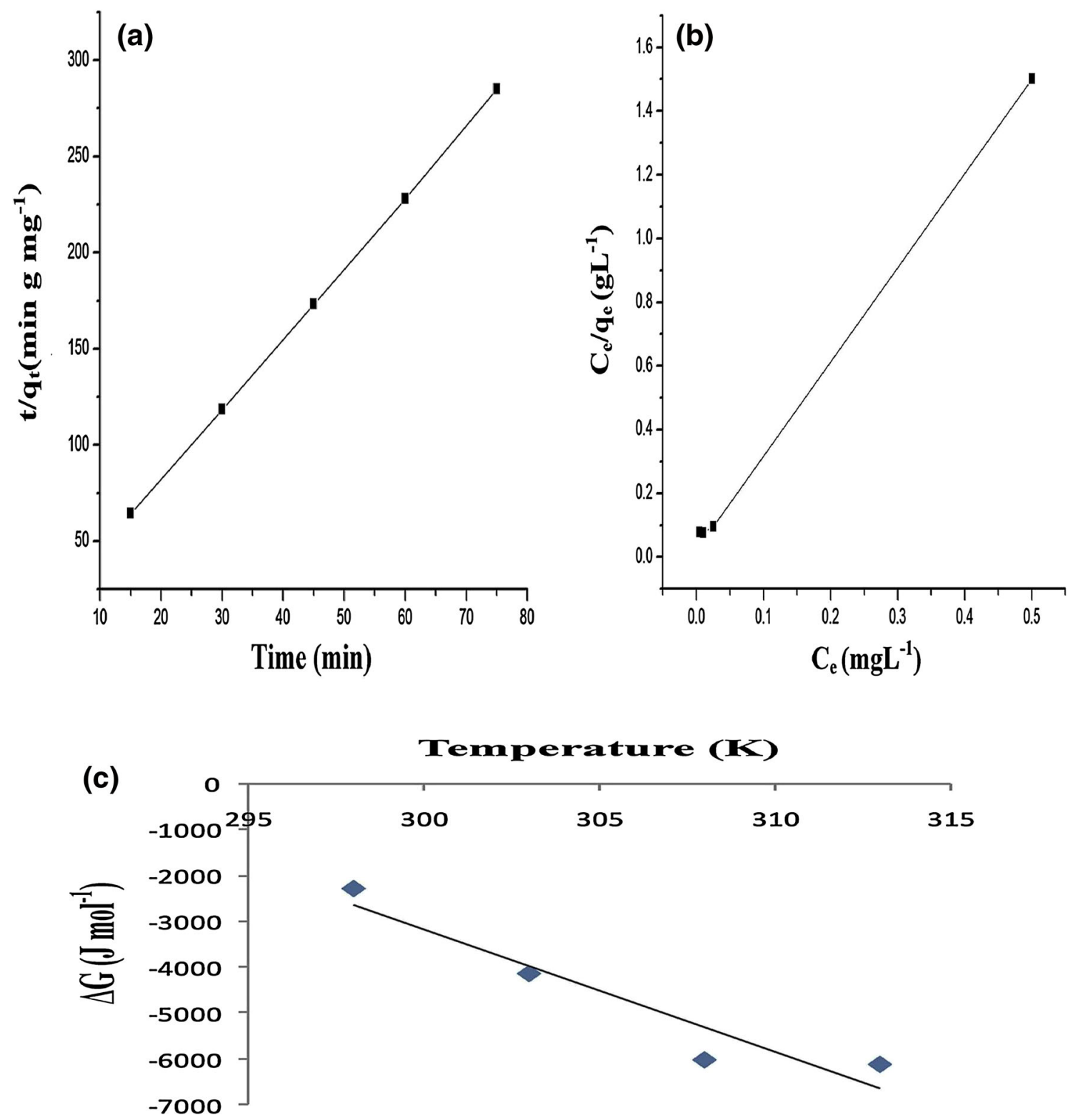

Fig. 5 a Pseudo-second-order kinetics, b Langmuir isotherm and c Gibbs free energy change versus temperature of As(V) onto SAB-MBH

parameters found from the equilibrium model show some adsorption mechanism insight, properties and affinity of the adsorbent surface.

The isotherm of Langmuir model provides information about the adsorptive capacity and broad equilibrium behavior. The following equation used to describe the model

$$
\frac{C_{\mathrm{e}}}{q_{\mathrm{e}}}=\frac{C_{\mathrm{e}}}{Q_{\mathrm{m}}}+\frac{1}{K_{\mathrm{L}} Q_{\mathrm{m}}},
$$

where $C_{\mathrm{e}}$ is the equilibrium adsorbate concentration at liquid phase $\left(\mathrm{mg} \mathrm{L}^{-1}\right), q_{\mathrm{e}}$ is the equilibrium adsorbate concentration at solid phase $\left(\mathrm{mg} \mathrm{g}^{-1}\right), Q_{\mathrm{m}}$ is the maximum adsorption capacity $\left(\mathrm{mg} \mathrm{g}^{-1}\right)$, and $K_{\mathrm{L}}$ is the adsorption equilibrium constant $\left(\mathrm{L} \mathrm{mg}^{-1}\right)$.
The plot between $\frac{C_{\mathrm{e}}}{q_{\mathrm{e}}}$ vs $C_{\mathrm{e}}$ of Langmuir isotherm indicates the isotherm constant value of $K_{\mathrm{L}}$ and $Q_{\mathrm{m}}$ from the slope and intercept of the graph, respectively (Fig. 5b).

Freundlich equilibrium model is associated with heterogeneous surface where low to intermediate concentration ranges are functional. The following equation can satisfactorily describe the model

$\log q_{\mathrm{e}}=\log K_{\mathrm{F}}+\left(\frac{1}{n}\right) \log C_{e}$,

where $K_{\mathrm{F}}$ and $n$ are Freundlich constants linked to adsorption capacity and adsorption intensity, respectively. These two constants can be estimated from the intercept and slope of the linear plot of $\log q_{\mathrm{e}}$ vs $\log C_{\mathrm{e}}$. 
The indication of adsorption favorability depends on the value of $n$.

Temkin isotherm model signifies the heat of the adsorption and the adsorbent-adsorbate interaction. For the Temkin isotherm model, following equation is used

$q_{\mathrm{e}}=B_{\mathrm{T}} \operatorname{In} K_{\mathrm{T}}+B_{\mathrm{T}} \operatorname{In} C_{\mathrm{e}}$,

where $q_{\mathrm{e}}$ is the quantity of $\mathrm{As}(\mathrm{V})$ adsorbed at equilibrium $\left(\mathrm{mg} \mathrm{g}^{-1}\right), B_{\mathrm{T}}$ is the Temkin adsorption isotherm constant or heat of adsorption, where $B_{\mathrm{T}}$ is the $(R T / b), R$ is the universal gas constant and $T$ is the temperature in kelvin, $K_{\mathrm{T}}$ is the Temkin equilibrium binding constant or the maximum binding energy $\left(\mathrm{L} \mathrm{mg}^{-1}\right)$, and $C_{\mathrm{e}}$ is the adsorbate concentration at equilibrium liquid phase $\left(\mathrm{mg} \mathrm{L}^{-1}\right)$.

The values of $B_{\mathrm{T}}$ and $K_{\mathrm{T}}$ were calculated from the plot of $q_{\mathrm{e}}$ against $\ln C_{\mathrm{e}}$.

The Dubinin-Radushkevich (D-R) model is generally expressing the adsorption mechanism. It is applied to differentiate between physical and chemical adsorption. It is expressed by the subsequent equation

$\ln q_{\mathrm{e}}=\ln q_{\mathrm{d}}-2 \beta \varepsilon^{2}$,

where $q_{d}$ is the Dubinin-Radushkevich isotherm constant related to the degree of sorbate sorption by the sorbent surface $(\mathrm{mg} / \mathrm{g}), \beta$ is the mean free energy coefficient of adsorption, $\quad \varepsilon=$ Polanyi $\quad$ potential $=R \operatorname{In}\left(1+1 / C_{\mathrm{e}}\right)$, where $R$ is the Gas constant $\left(8.314 \mathrm{~J} \mathrm{~mol}^{-1} \mathrm{~K}^{-1}\right)$ and $T$ is the temperature $(K)$.

The mean free energy of the each adsorbate molecule can be mathematically expressed by the following equation (Kundu and Gupta 2006):

$E=\frac{1}{\sqrt{2 \beta}}$,

$E$ is the mean free energy of the adsorption (E).

The comparative analysis of the four isotherm models was done on the basis of linear coefficient $R^{2}$ value and the isotherm was validated by Chi square test.

The Chi square test $\left(\chi^{2}\right)$ was calculated by the following equation:

$\chi^{2}=\sum \frac{\left(q_{\text {exp }}-q_{\text {mea }}\right)^{2}}{q_{\text {mea }}}$

where $q_{\exp }$ is the experimental amount of arsenic concentration at equilibrium and $q_{\text {mea }}$ is the measured or calculated amount of arsenic concentration at equilibrium.

Table 3 shows the diverse isotherm parameter with their corresponding values and from the Langmuir isotherm it was seen that the $R^{2}$ value is close to unity or unity as compared to the other three isotherm models. The $R^{2}$ value indicates the fit of experimental data into the liner isotherm equation; the higher the $R^{2}$ value the better is the goodness of fit.
Table 3 Isotherm parameters for $\mathrm{As}(\mathrm{V})$ removal using activated MBH carbon

\begin{tabular}{ll}
\hline & Values \\
\hline Langmuir & \\
$Q_{\text {max }}\left(\mathrm{mg} \mathrm{g}^{-1}\right)$ & 0.36 \\
$K_{\mathrm{L}}\left(\mathrm{L} \mathrm{mg}^{-1}\right)$ & 0.3385 \\
$R_{\mathrm{L}}$ & 0.5963 \\
$R^{2}$ & 0.999 \\
$\chi^{2}$ & 0.016 \\
Freundlich & \\
$K_{\mathrm{F}}\left(\mathrm{mg} \mathrm{g}^{-1}\left(\mathrm{mg} \mathrm{L}^{-1}\right)_{\mathrm{F}}^{-1 / n}\right)$ & 0.7378 \\
$n_{\mathrm{F}}$ & 3.2679 \\
$R^{2}$ & 0.723 \\
$\chi^{2}$ & 5.702 \\
Temkin & \\
$B_{\mathrm{T}}$ & 0.054 \\
$K_{\mathrm{T}}\left(\mathrm{L} \mathrm{mg}^{-1}\right)$ & 1474.83 \\
$R^{2}$ & 0.839 \\
$\chi^{2}$ & 0.043 \\
$\mathrm{D}-\mathrm{R} \mathrm{model}$ & \\
$q\left(\mathrm{mg} \mathrm{g}^{-1}\right)$ & \\
$\beta$ & 0.345 \\
$E\left(\mathrm{~kJ} \mathrm{~mol}^{-1}\right)$ & $1.11 \times 10^{-3}$ \\
$R^{2}$ & 21.218 \\
$\chi^{2}$ & 0.984 \\
\hline
\end{tabular}

Experimental conditions: adsorbent dosage $0.75 \mathrm{~g}$; $\mathrm{pH} 3$, agitation speed $160 \mathrm{rpm}$; temperature $308 \mathrm{~K}$

The error factor when considering, it is shown that low $\chi^{2}$ value in Langmuir model has better represented the equilibrium data into the equation. An outstanding fit of the adsorption data into the Langmuir isotherm model established that the adsorption is monolayer where each molecule of adsorption had identical activation energy and negligible sorbate-sorbate interaction (Kannan and Sundaram 2001). Lastly to confirm the results, Langmuir adsorption model was checked by the $R_{\mathrm{L}}$ value which is a dimensionless constant or separation factor or equilibrium parameter. $R_{\mathrm{L}}$ is computed by means of the subsequent equation

$R_{\mathrm{L}}=\frac{1}{1+K_{\mathrm{L}} C_{0}}$

where $C_{0}$ is the initial $\mathrm{As}(\mathrm{V})$ concentration $\left(\mathrm{mg} \mathrm{L}^{-1}\right)$.

The value of $R_{\mathrm{L}}$ indicates the isotherm nature which may be irreversible $\left(R_{\mathrm{L}}=0\right)$, favorable $\left(0<R_{\mathrm{L}}<1\right)$ or unfavorable $\left(R_{\mathrm{L}}=1\right)$. Investigational data suggest the value of $R_{\mathrm{L}}$ was in between 0 and 1 ; which confirm adsorption was favorable and excellent fit of Langmuir model to describe the investigational data. Apart from Langmuir model, the parameters of D-R model have also some significance due to its $R^{2}$ value (0.984) and low Chi square value (0.378). From D-R model, the magnitude of E 
Table 4 Comparative adsorptive capacity of prepared SAC-MBH and other different adsorbent found in the literature towards the adsorption of As $(\mathrm{V})$

\begin{tabular}{lll}
\hline Adsorbent & Adsorptive capacity $\left(\mathrm{mg} \mathrm{g}^{-1}\right)$ & References \\
\hline Iron oxide/activated carbon composite & 0.4123 & Yao et al. (2014) \\
Iron oxide-coated sand & 0.043 & Thirunavukkarasu et al. (2002) \\
Untreated GAC & 0.038 & Gu et al. (2005) \\
Steam activated charcoal from mung bean husk & $\mathbf{0 . 3 6}$ & Present study \\
Aluminum-loaded coral limestones & 0.15 & Ohki et al. (1996) \\
Granular ferric oxide & 0.004 & Badruzzaman et al. (2004) \\
Olivier soil & 0.42 & Zhang and Selim (2005) \\
Coconut shell carbon with $3 \%$ ash & 2.4 & Lorenzen et al. (1995) \\
Commercial nanomagnetic & 0.205 & Türk et al. (2010) \\
$\mathrm{HBC}_{-} \mathrm{Fe}_{3} \mathrm{O}_{4}-\mathrm{MnO}_{2}$ bio composite & 1.46 & Zhu et al. (2015) \\
$\mathrm{Magnetic} \mathrm{nanoparticle}$ & 0.485 & Shipley et al. (2010)
\end{tabular}

Table 5 Thermodynamics parameters for $\mathrm{As}(\mathrm{V})$ removal by using SAC-MBH

\begin{tabular}{llll}
\hline Temperature $(\mathrm{K})$ & $\Delta G\left(\mathrm{~kJ} \mathrm{~mol}^{-1}\right)$ & $\Delta H\left(\mathrm{~kJ} \mathrm{~mol}^{-1}\right)$ & $\begin{array}{l}\Delta S \\
\left(\mathrm{~J} \mathrm{~mol}^{-1} \mathrm{~K}^{-1}\right)\end{array}$ \\
\hline 298 & -2.301 & -76.909 & 266.9 \\
303 & -4.151 & & \\
308 & -6.027 & & \\
313 & -6.125 & & \\
\hline
\end{tabular}

Experimental conditions: adsorbent dosage $0.75 \mathrm{~g}$; $\mathrm{pH} 3$, agitation speed $160 \mathrm{rpm}$; temperature $308 \mathrm{~K}$

$\left(21.218 \mathrm{~kJ} \mathrm{~mol}^{-1}\right)$ indicates the process followed chemisorptions adsorption. The maximum adsorption capacity of $\mathrm{As}(\mathrm{V})$ by SAC-MBH has been compared with other adsorbents found in different literature (Table 4).

\section{Thermodynamic studies}

Thermodynamic behavior of a system can be understood by the help of the following equation:

$\Delta G^{0}=-R T \ln K_{\mathrm{c}}$,

$K_{\mathrm{c}}=\frac{C_{\mathrm{a}}}{C_{\mathrm{e}}}$,

$\Delta G^{0}=\Delta H^{0}-T \Delta S^{0}$

where $K_{\mathrm{c}}$ is adsorption distribution coefficient, $C_{\mathrm{a}}$ and $C_{\mathrm{e}}$ are the equilibrium arsenic concentrations on the adsorbent and in the solution, respectively. $\Delta G^{0}$ is the Gibbs free energy change, $\Delta H^{0}$ is the enthalpy change and $\Delta S^{0}$ is the entropy change (Yao et al. 2010).

A plot of $\Delta G^{0}$ versus $T$ gives the slope and intercept, from that the values of $\Delta S^{0}$ and $\Delta H^{0}$ can be measured (Fig. 5c).

Gibbs free energy for the adsorption of $\mathrm{As}(\mathrm{V})$ by SAC$\mathrm{MBH}$ was obtained from the Eq. (15) and presented in Table 5.
The negative value of $\Delta H^{0}$ strongly supports the exothermic nature of adsorption while the negative value of $\Delta S^{0}$ suggests that the process was enthalpy driven. At all temperatures, the negative values of $\Delta G^{0}$ confirmed the spontaneous and feasible adsorption process. By increasing the temperature, the value of $\Delta G^{0}$ becomes more negative that suggests that the higher temperature makes the adsorption favorable.

\section{Modeling of the process}

\section{Response surface methodology}

The experimental design of the modeling of removal process was carried out and results were obtained according to CCD matrix (Table 1). Experimental data of $\mathrm{As}(\mathrm{V})$ removal process were fitted into different models (linear, interactive, quadratic and cubic) using two tests, i.e., the sequential model sum of squares and lack of fit test were carried to find the best fitted model and the model summary statistics are specified in Table 6. It was clear from the results that high value of determination of coefficient $\left(R^{2}\right)$, adjusted determination of coefficient $\left(R_{\mathrm{adj}}^{2}\right)$, predicted determination of coefficient $\left(R_{\text {pre }}^{2}\right)$ while low value of $p$ values in quadratic model proved its competency among the different models. In addition to this, the experimental data were successfully covered in this model. The quadratic model was expressed in terms of coded variables (Eq. 19) and in terms of actual variables (Eq. 20).

$$
\begin{aligned}
\% \text { Removal of As }(\mathrm{V})= & +94.85-1.95 \times A+0.60 \times B \\
& +0.80 \times C-0.63 \times A \times B \\
& +0.75 \times A \times C+0.50 \times B \times \\
& C-1.39 \times A^{2}-2.27 \times B^{2}-3.33 \times C^{2}
\end{aligned}
$$




$$
\begin{aligned}
& \text { \% Remvoal of As (V) } \\
& =+65.53489+1.66153 \times \mathrm{pH}+0.18179 \\
& \times \text { Agitation speed } \\
& +0.028224 \times \text { Dosage }-3.84615 \mathrm{E}-003 \times \mathrm{pH} \\
& \times \text { Agitation speed } \\
& +7.50000 \mathrm{E}-004 \times \mathrm{pH} \times \text { Dosage }+1.92308 \mathrm{E}-005 \\
& \times \text { Agitation speed } \times \text { Dosage }-0.22226 \times \mathrm{pH}^{2} \\
& -5.37990 \mathrm{E}-004 \\
& \times \text { Agitation speed }^{2}-2.08354 \mathrm{E}-005 \times \text { Dosage }^{2}
\end{aligned}
$$

Quadratic model's statistical significance was checked using ANOVA (analysis of variance). The results of ANOVA for second order response surface model are shown in Table 6. Different parameters associated with quadratic model proved that the model is significant such as 1 . High fishers $F$ value (94.43). 2. Very low probability value $(<0.0001)$. 3. Multiple correlation coefficient $\left(R^{2}\right)$ value $(0.9946)$ was fairly high so significant for Goodness of fit test. 4. Predicted multiple correlation coefficient value $(0.9277)$ was in a reasonable good agreement with the adjusted multiple correlation value (0.9778). 5. The lack of fit value is less than 0.05. 6 . Coefficient of variance $(\mathrm{CV})$ value (0.66) is low suggesting precision and reliability of the data. 7. The values of "probability $>F$ " less than 0.0500 indicate that the model term is significant and 8 coefficients of the main, square as well as interaction effects of model terms are significant.

Effect of adsorbent dosage and $p H$ on $A s(V)$ removal Prediction of $\mathrm{As}(\mathrm{V})$ removal by the combined effect of adsorbent dosage and solution $\mathrm{pH}$ is described in three dimensional plot (Fig. 6a). Increasing the adsorbent dosage while decreasing the $\mathrm{pH}$ of the solution increases the \% removal of $\mathrm{As}(\mathrm{V})$. This phenomena occurs as more

\begin{tabular}{|c|c|c|c|c|c|c|c|}
\hline \multicolumn{2}{|l|}{ Source } & Standard deviation & $R^{2}$ & Adjusted $R^{2}$ & Predicted $R^{2}$ & PRESS & Remarks \\
\hline \multicolumn{8}{|c|}{ RSM model fit summary statistics } \\
\hline \multicolumn{2}{|l|}{ Linear } & 3.87 & 0.214556 & 0.067285 & -0.11991 & 341.726 & \\
\hline $2 \mathrm{FI}$ & & 4.21 & 0.246099 & -0.10186 & -1.02718 & 618.5689 & \\
\hline Quadratic & & 0.6 & 0.98833 & 0.977828 & 0.927697 & 22.06223 & Suggested \\
\hline Cubic & & 0.56 & 0.993758 & 0.980233 & 0.222053 & 237.3807 & Aliased \\
\hline Source & Sum of squares & \multicolumn{2}{|c|}{ Degree of freedom $(d f)$} & Mean square & $F$-value & \multicolumn{2}{|l|}{ Probability $>F$} \\
\hline \multicolumn{8}{|l|}{ ANOVA } \\
\hline Model & 301.584 & 9 & \multicolumn{2}{|r|}{33.5} & 94.1 & $<0.0001$ & \multirow[t]{11}{*}{ Significant } \\
\hline$A$ & 51.86 & 1 & \multicolumn{2}{|r|}{51.86} & 145.65 & $<0.0001$ & \\
\hline$B$ & 4.929 & 1 & & 4.92 & 13.84 & 0.0040 & \\
\hline$C$ & 8.678 & 1 & & 8.68 & 24.37 & 0.0006 & \\
\hline$A B$ & 3.125 & 1 & & 3.12 & 8.78 & 0.0142 & \\
\hline$A C$ & 4.5 & 1 & & 4.5 & 12.64 & 0.0052 & \\
\hline$B C$ & 2 & 1 & & 2 & 5.617 & 0.0393 & \\
\hline$A$ & 27.809 & 1 & & 27.81 & 78.09 & $<0.0001$ & \\
\hline$B$ & 74.45 & 1 & & 74.46 & 209.1 & $<0.0001$ & \\
\hline$C$ & 160.15 & 1 & & 160.16 & 449.79 & $<0.0001$ & \\
\hline Residual & 3.56 & 10 & & 0.356 & & & \\
\hline Lack of fit & 2.727 & 5 & & 0.545496 & 3.27 & 0.1095 & Not significant \\
\hline Pure error & 0.833 & 5 & & 0.166667 & & & \\
\hline Total & 305.14 & 19 & & & & & \\
\hline Std.dev. & $\mathrm{Me}$ & & & $R^{2}$ & Adj. R & & Predicted $R^{2}$ \\
\hline Model statist & & & & & & & \\
\hline 0.596725 & & 0.6 & & 0.988 & 0.977 & & 0.927 \\
\hline
\end{tabular}
adsorbent dosage indicates more adsorbent mass so increases adsorbent surface area that ultimately leads to more sorption site for adsorption. The adsorbed $\mathrm{As}(\mathrm{V})$ amount increases with decrease in solution $\mathrm{pH}$. The explanation of the fact is that when the solution $\mathrm{pH}$ is less than pHpzc, then the adsorbent surface $(\mathrm{pHpzc}=8.6)$ becomes positively charged where the surface of arsenate

Table 6 RSM Model fit summary statistics and ANOVA analysis of RSM model 
Fig. 6 Three-dimensional plot showing the interaction effect of a $\mathrm{pH}$ and dosage, $\mathbf{b}$ agitation speed and dosage and $\mathbf{c} \mathrm{pH}$ and agitation speed of $\mathrm{SAB}-\mathrm{MBH}$ on removal of $\mathrm{As}(\mathrm{V})$
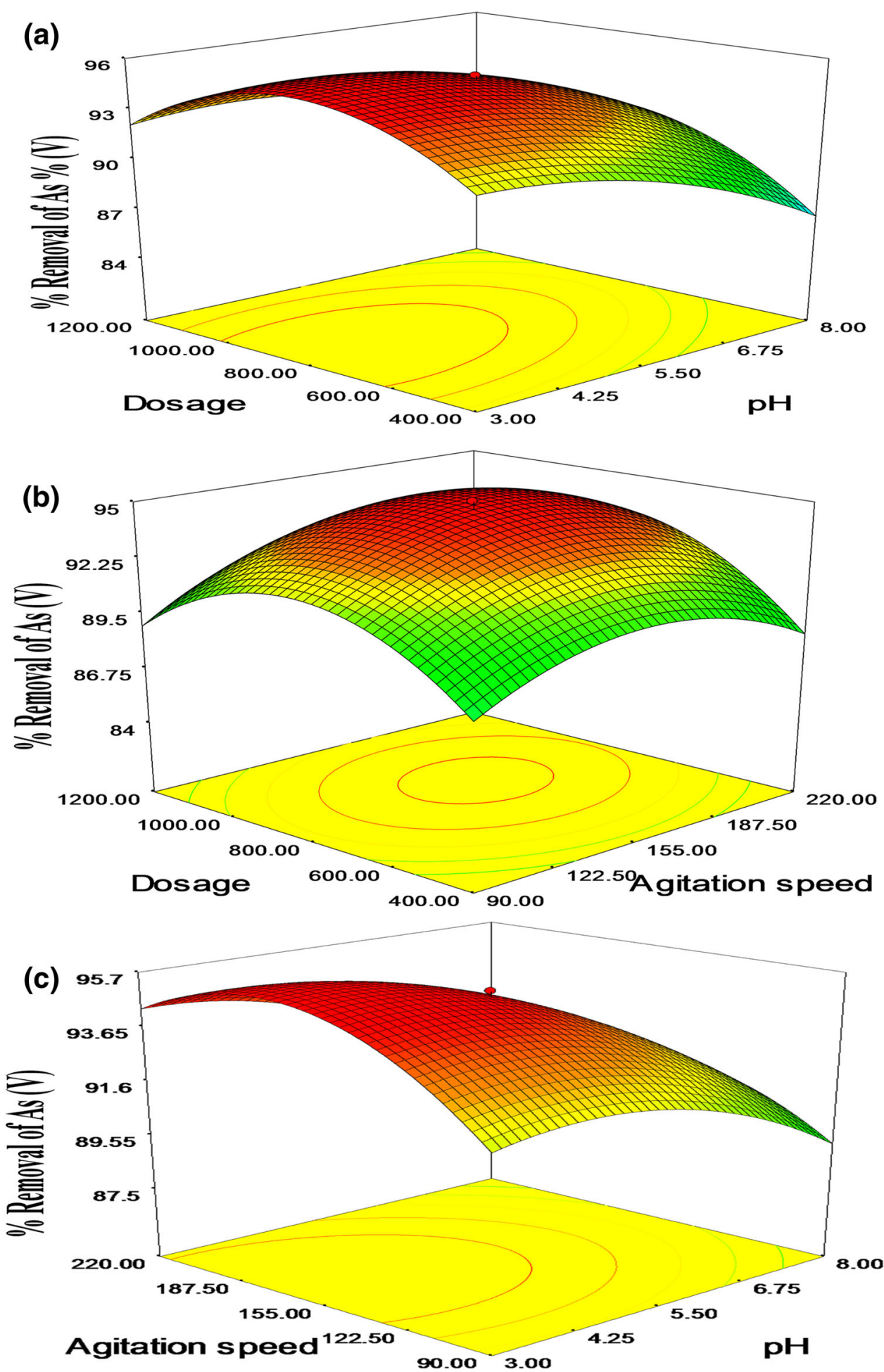

$(\mathrm{pKa}=6.97)$ becomes more negative at $\mathrm{pH}$; thus, negaand agitation speed was shown in the three-dimensional plot as indicated in Fig. 6b. Both independent variables have positive effect on the As(V) removal so increasing the both variables has synergistic effect on this process.

Effect of $p H$ and agitation speed $A s(V)$ removal Figure $6 \mathrm{c}$ demonstrates the interactive effects of two independent 

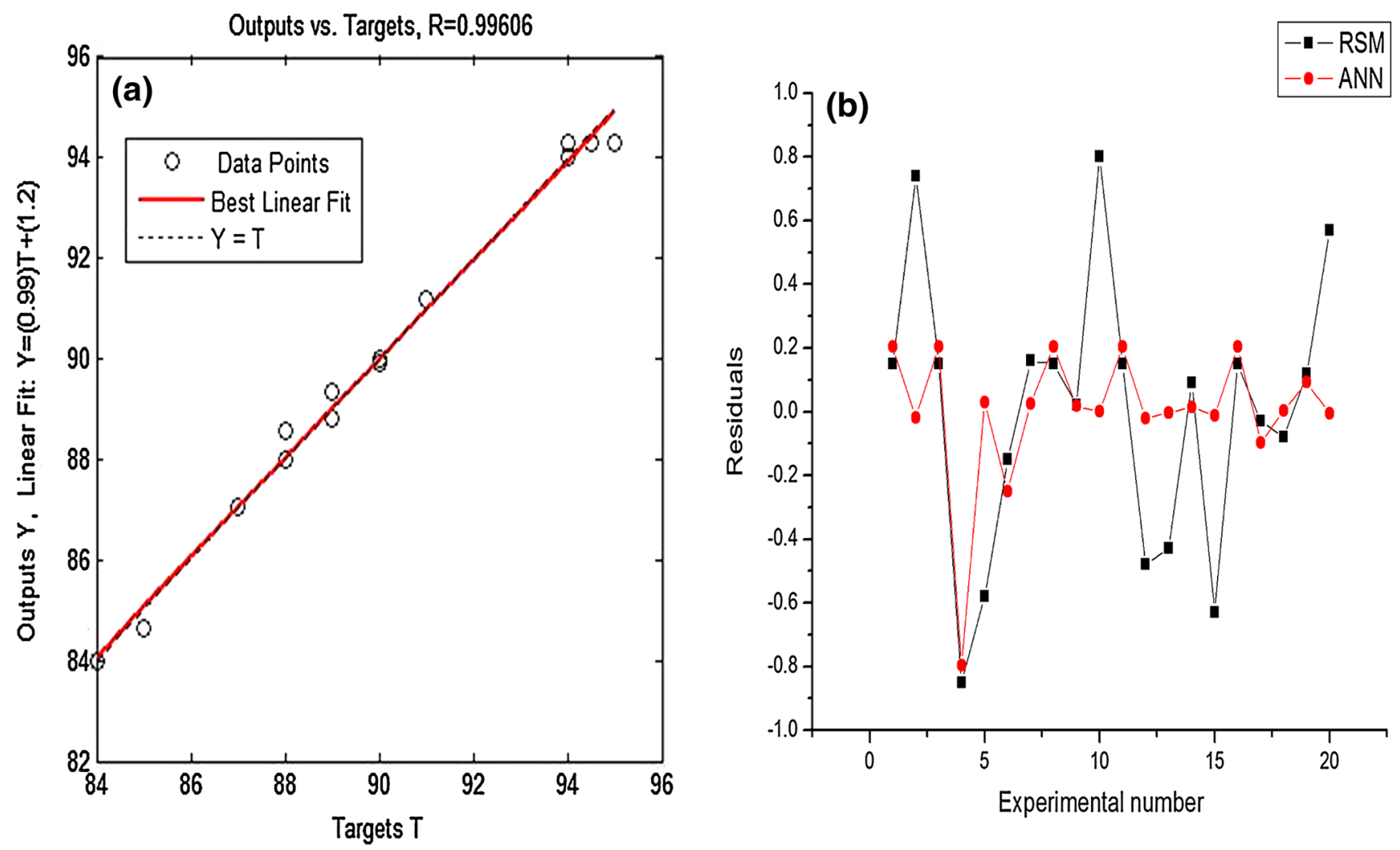

Fig. 7 a Regression plot of ANN model. b Residuals distribution patterns of RSM and ANN

Table 7 Trial and error method using transfer function (poslin and purelin) for \% removal of As(V) by ANN model

\begin{tabular}{lll}
\hline Hidden layer algorithm & Output layer function & Correlation coefficient \\
\hline Levenberg-Marqardt back propagation & Trainlm & 0.9984 \\
Resillient back propagation & Trainrp & 0.965 \\
Scaled conjugate gradient back propagation & Traincgp & 0.588 \\
Conjugate gradient back propagation with Polak-Ribiere updates & Trainscg & 0.212 \\
Gradient descent with momentum and adaptive learning rate back propagation & Traingdx & 0.326 \\
\hline
\end{tabular}

variables, i.e., $\mathrm{pH}$ and agitation speed. Regression analysis indicates the model term $\mathrm{pH}$ and agitation speed has net positive effect on $\mathrm{As}(\mathrm{V})$ removal. Collective $p$ value (0.0393) of these two parameters is lesser than 0.1000 signifying the combined model terms.

\section{Artificial neural network training for the optimization of the $\mathrm{As}(\mathrm{V})$ removal model}

Input data were feed into the ANN architectures where algorithm (error back propagation) was used to train the process. The same experimental matrix of CCD was used to train the input and output data of ANN modeling of the process. Independent variables, i.e., dosage, $\mathrm{pH}$ and $\mathrm{rpm}$, are selected as input nodes where dependent variables response or the removal of $\mathrm{As}(\mathrm{V})$ is the output nodes. In the hidden layer, nonlinear transformations were done to test different types of algorithm to select the best network which gave $R^{2}$ (coefficient of correlation) that is very close to one.

Training of ANN network to optimize the removal process is a crucial step. The selection of POSLIN (positive linear transfer function) for input data where PURELIN was selected for output data to train the ANN. The best ANN network was selected by optimizing neuron present within the hidden layer. After feeding the data and running the software in ANN, we found the best correlation coefficient value (0.99) from the regression plot of the trained network (Fig. 7a). A high correlation coefficient that is closer to 1 signified the neural network modeling reliability with the experimental data. Among the different algorithm used in ANN (Table 7), Levenberg-Marquardt back 
propagation (Trainlm) showed the best fitted algorithm to explain the ANN networking for the removal process.

\section{Comparison of RSM and ANN network for the removal of $\mathrm{As}(\mathrm{V})$}

Utilizing RSM and ANN modeling process, linear and nonlinear multivariate regression problems are solved. The difference between the experimental value and model predicted value (RSM and ANN) is compared in Table 1. The residuals distribution pattern of RSM and ANN is shown in Fig. 7(b). Compared to RSM model, the residual fluctuation of ANN models is less diverge, normal and minute. Further both models are compared using three statistical estimators, i.e., root mean squared error (RMSE), coefficient of determination $\left(R^{2}\right)$ and absolute average deviation (AAD)

$\mathrm{RMSE}=\left(\frac{1}{n} \sum_{i=1}^{n}\left(T_{\% \text { removal,predict }}-T_{\% \text { removal }, \exp }\right)^{2}\right)^{1 / 2}$, simulates non-linear form while overcoming the limitations of quadratic non-linear correlation assumption of RSM.

\section{Conclusion}

Isotherm, kinetics, thermodynamics and optimization of the process parameter associated with adsorption of pentavalent arsenic onto mung bean husk derived activated carbon have been studied in detail. Experimentally the maximum adsorptive removal of arsenic has been observed to take place at an adsorbent dosage $0.75 \mathrm{~g}, \mathrm{pH} 3.0$, agitation speed 160 and temperature of $308 \mathrm{~K}$ in case of $2 \mathrm{ppm} \mathrm{As}(\mathrm{V})$. Out of four isotherm models tested, the fitting order with respect to coefficient of correlation was Langmuir $>$ D-R model $>$ Temkin $>$ Freundlich. The kinetic aspect of the data showed that the adsorption followed pseudo-second-order model. The heat of sorption was found to be $\left(21.218 \mathrm{~kJ} \mathrm{~mol}^{-1}\right)$ which indicates that the sorptive removal process was chemisorption. Thermodynamic parameters suggest that the adsorption process was exothermic, spontaneous, and feasible in nature and higher

$R^{2}=\frac{\sum_{i=1}^{n}\left(T_{\% \text { removal }, \text { experimental }}-\overline{T_{\% \text { removal }, \mathrm{cal}}}\right)^{2}}{\sum_{i=1}^{n}\left(T_{\% \text { removal }, \text { experimental }}-\overline{T_{\% \text { removal }, \mathrm{cal}}}\right)^{2}+\left(T_{\% \text { removal } \text { experimental }}-T_{\% \text { removal,cal }}\right)^{2}}$,

$\mathrm{AAD}=\left(\frac{1}{n} \sum_{i=1}^{n}\left(\frac{T_{\% \text { removal,predict }}-T_{\% \text { removal }, \text { exp }}}{T_{\% \text { removal }, \exp }}\right)\right) \times 100$,

where $n$ is the number of points, $T \%$ removal, predict is the predicted value, $T \%$ removal, exp is the actual value, and the symbol '-' is the average of the related values.

Statistical comparison (Table 8) showed that both models have good quality of data fitting and estimating capability, although ANN has some slight edge over RS. The advantage of ANN is its flexibility and non-requirement of standard experimental design. Its disadvantages include no combined parametric effect on the process. In general, ANN approach is a trustworthy, rational and

Table 8 Comparative statistical analysis of RSM and ANN

\begin{tabular}{lll}
\hline Parameters & RSM & ANN \\
\hline RMSE & 0.422 & 0.215 \\
$R^{2}$ & 0.9883 & 0.99698 \\
ADD $(\%)$ & 0.00093 & 0.00011 \\
\hline
\end{tabular}

temperature was favorable for adsorption process. An effort has been made to model the removal process utilizing RSM and ANN network approaches. The process modeling done by ANN $\left(R^{2}=0.9969\right)$ has some minute edge over RSM $\left(R^{2}=0.9883\right)$ although in general both the models have some good optimizing capability.

Acknowledgements The authors gratefully acknowledge the monetary support from the Ministry of Human Resource Development (MHRD), India for executing this research work.

Open Access This article is distributed under the terms of the Creative Commons Attribution 4.0 International License (http:// creativecommons.org/licenses/by/4.0/), which permits unrestricted use, distribution, and reproduction in any medium, provided you give appropriate credit to the original author(s) and the source, provide a link to the Creative Commons license, and indicate if changes were made.

\section{References}

Ali I, Al-Othman ZA, Alwarthan A, Asim M, Khan TA (2014) Removal of arsenic species from water by batch and column 
operations on bagasse fly ash. Environ Sci Pollut 21(5):3218-3229

Asadullah M, Jahan I, Ahmed MB, Adawiyah P, Malek NH, Rahman MS (2014) Preparation of microporous activated carbon and its modification for arsenic removal from water. J Ind Eng Chem 20(3):887-896

Badruzzaman M, Westerhoff P, Knappe DR (2004) Intraparticle diffusion and adsorption of arsenate onto granular ferric hydroxide (GFH). Water Res 38(18):4002-4012

Bissen M, Frimmel FH (2003) Arsenic-a review. Part II: oxidation of arsenic and its removal in water treatment. Acta Hydrochim Hydrobiol 31(2):97-107

Borho M, Wilderer P (1996) Optimized removal of arsenate (III) by adaptation of oxidation and precipitation processes to the filtration step. Water Sci Technol 34(9):25-31

Budinova T, Savova D, Tsyntsarski B et al (2009) Biomass wastederived activated carbon for the removal of arsenic and manganese ions from aqueous solutions. Appl Surf Sci 255(8):4650-4657

Chang SH, Teng TT, Ismail N (2011) Optimization of $\mathrm{Cu}$ (II) extraction from aqueous solutions by soybean-oil-based organic solvent using response surface methodology. Water Air Soil Pollut 217(1-4):567-576

Chien S, Clayton W (1980) Application of Elovich equation to the kinetics of phosphate release and sorption in soils. Soil Sci Soc Am J 44(2):265-268

Dubinin M (1960) The potential theory of adsorption of gases and vapors for adsorbents with energetically nonuniform surfaces. Chem Rev 60(2):235-241

Fogarassy E, Galambos I, Bekassy-Molnar E, Vatai G (2009) Treatment of high arsenic content wastewater by membrane filtration. Desalination 240(1):270-273

Gu Z, Fang J, Deng B (2005) Preparation and evaluation of GACbased iron-containing adsorbents for arsenic removal. Environ Sci Technol 39(10):3833-3843

Hansen HK, Nunez P, Raboy D, Schippacasse I, Grandon R (2007) Electrocoagulation in wastewater containing arsenic: comparing different process designs. Electrochim Acta 52(10):3464-3470

Ho Y, Ng J, McKay G (2000) Kinetics of pollutant sorption by biosorbents: review. Sep Purif Rev 29(2):189-232

Jiang J-Q, Ashekuzzaman S, Jiang A, Sharifuzzaman S, Chowdhury SR (2012) Arsenic contaminated groundwater and its treatment options in Bangladesh. Int $\mathrm{J}$ Environ Res Public Health 10(1): $18-46$

Kalderis D, Koutoulakis D, Paraskeva P et al (2008) Adsorption of polluting substances on activated carbons prepared from rice husk and sugarcane bagasse. Chem Eng J 144(1):42-50

Kannan N, Sundaram MM (2001) Kinetics and mechanism of removal of methylene blue by adsorption on various carbons-a comparative study. Dyes Pigments 51(1):25-40

Khan TA, Nazir M (2015) Enhanced adsorptive removal of a model acid dye bromothymol blue from aqueous solution using magnetic chitosan-bamboo sawdust composite: batch and column studies. Environ Prog Sustain Energy 34(5):1444-1454

Khan TA, Sing VV (2010) Removal of cadmium(II), lead(II), and chromium(VI) ions from aqueous solution using clay. Toxicol Environ Chem 92(8):1435-1446

Khan TA, Chaudhry SA, Ali I (2013) Thermodynamic and kinetic studies of $\mathrm{As}(\mathrm{V})$ removal from water by zirconium oxide-coated marine sand. Environ Sci Pollut Res 20(8):5425-5440

Khan TA, Sharma S, Khan EA, Mukhlif AA (2014) Removal of congo red and basic violet 1 by chir pine (Pinus roxburghii) sawdust, a saw mill waste: batch and column studies. Environ Sci Pollut Res 96(4):555-568

Khan TA, Khan EA, Shahjahan RA (2016) Adsorptive uptake of basic dyes from aqueous solution by novel brown linseed deoiled cake activated carbon: equilibrium isotherms and dynamics. J Environ Chem Eng 4(3):3084-3095

Khan TA, Rahman R, Khan EA (2017) Adsorption of malachite green and methyl orange onto waste tyre activated carbon using batch and fixed-bed techniques: isotherm and kinetics modelling. Model Earth Syst Environ 3:38. doi:10.1007/s40808-017-0284-1

Khataee A, Khani A (2009) Modeling of nitrate adsorption on granular activated carbon (GAC) using artificial neural network (ANN). Int J Chem React Eng 7(1)

Kumar A, Kumar S, Kumar S (2003) Adsorption of resorcinol and catechol on granular activated carbon: equilibrium and kinetics. Carbon 41(15):3015-3025

Kundu S, Gupta A (2006) Arsenic adsorption onto iron oxide-coated cement (IOCC): regression analysis of equilibrium data with several isotherm models and their optimization. Chem Eng J 122(1):93-106

Lewinsky AA (2007) Hazardous materials and wastewater: treatment, removal and analysis. Nova Publishers, New York

Li Q, Xu X, Cui H et al (2012) Comparison of two adsorbents for the removal of pentavalent arsenic from aqueous solutions. J Environ Manag 98:98-106

Liu X, Ao H, Xiong X, Xiao J, Liu J (2012) Arsenic removal from water by iron-modified bamboo carbon. Water Air Soil Pollut 223(3):1033-1044

Lorenzen L, Van Deventer J, Landi W (1995) Factors affecting the mechanism of the adsorption of arsenic species on activated carbon. Miner Eng 8(4):557-569

Mandal BK, Suzuki KT (2002) Arsenic round the world: a review. Talanta 58(1):201-235

Mohan D, Pittman CU (2007) Arsenic removal from water/wastewater using adsorbents-a critical review. J Hazard Mater 142(1):1-53

Mohan D, Rajput S, Singh VK, Steele PH, Pittman CU (2011a) Modeling and evaluation of chromium remediation from water using low cost bio-char, a green adsorbent. J Hazard Mater 188(1):319-333

Mohan D, Sarswat A, Singh VK, Alexandre-Franco M, Pittman CU (2011b) Development of magnetic activated carbon from almond shells for trinitrophenol removal from water. Chem Eng J 172(2):1111-1125

Mondal P, Majumder C, Mohanty B (2008) Effects of adsorbent dose, its particle size and initial arsenic concentration on the removal of arsenic, iron and manganese from simulated ground water by $\mathrm{Fe}^{3+}$ impregnated activated carbon. J Hazard Mater 150(3):695-702

Mondal S, Sinha K, Aikat K, Halder G (2015) Adsorption thermodynamics and kinetics of ranitidine hydrochloride onto superheated steam activated carbon derived from mung bean husk. J Environ Chem Eng 3(1):187-195

Mondal S, Aikat K, Halder G (2016a) Biosorptive uptake of ibuprofen by chemically modified Parthenium hysterophorus derived biochar: equilibrium, kinetics, thermodynamics and modeling. Ecol Eng 92:158-172

Mondal S, Aikat K, Halder G (2016b) Ranitidine hydrochloride sorption onto superheated steam activated biochar derived from mung bean husk in fixed bed column. J Environ Chem Eng 4(1):488-497

Mondal S, Bobde K, Aikat K, Halder G (2016c) Biosorptive uptake of ibuprofen by steam activated biochar derived from mung bean husk: equilibrium, kinetics, thermodynamics, modeling and ecotoxicological studies. J Environ Manag 182:581-594

$\mathrm{Ng}$ JC (2005) Environmental contamination of arsenic and its toxicological impact on humans. Environ Chem 2(3):146-160

Ohki A, Nakayachigo K, Naka K, Maeda S (1996) Adsorption of inorganic and organic arsenic compounds by aluminium-loaded coral limestone. Appl Org Chem 10(9):747-752 
Pokhrel D, Viraraghavan T (2008) Arsenic removal from an aqueous solution by modified $A$. niger biomass: batch kinetic and isotherm studies. J Hazard Mater 150(3):818-825

Ranjan D, Talat M, Hasan S (2009) Rice polish: an alternative to conventional adsorbents for treating arsenic bearing water by upflow column method. Ind Eng Chem Res 48(23):10180-10185

Roy P, Mondal NK, Bhattacharya S, Das B, Das K (2013) Removal of arsenic(III) and arsenic(V) on chemically modified low-cost adsorbent: batch and column operations. Appl Water Sci 3(1):293-309

Shafique U, Ijaz A, Salman M et al (2012) Removal of arsenic from water using pine leaves. J Taiwan Inst Chem Eng 43(2):256-263

Shipley HJ, Yean S, Kan AT, Tomson MB (2010) A sorption kinetics model for arsenic adsorption to magnetite nanoparticles. Environ Sci Pollut Res 17(5):1053-1062

Song S, Lopez-Valdivieso A, Hernandez-Campos D, Peng C, Monroy-Fernandez M, Razo-Soto I (2006) Arsenic removal from high-arsenic water by enhanced coagulation with ferric ions and coarse calcite. Water Res 40(2):364-372

Thirunavukkarasu O, Viraraghavan T, Subramanian K, Tanjore S (2002) Organic arsenic removal from drinking water. Urban Water 4(4):415-421
Türk T, Alp I, Deveci H (2010) Adsorptive removal of arsenite from water using nanomagnetite. Desal Water Treat 24(1-3):302-307

Urbano BF, Rivas BL, Martinez F, Alexandratos SD (2012) Waterinsoluble polymer-clay nanocomposite ion exchange resin based on $N$-methyl-D-glucamine ligand groups for arsenic removal. React Funct Polym 72(9):642-649

Wickramasinghe S, Han B, Zimbron J, Shen Z, Karim M (2004) Arsenic removal by coagulation and filtration: comparison of groundwaters from the United States and Bangladesh. Desalination 169(3):231-244

Yao Z-Y, Qi J-H, Wang L-H (2010) Equilibrium, kinetic and thermodynamic studies on the biosorption of $\mathrm{Cu}(\mathrm{II})$ onto chestnut shell. J Hazard Mater 174(1):137-143

Yao S, Liu Z, Shi Z (2014) Arsenic removal from aqueous solutions by adsorption onto iron oxide/activated carbon magnetic composite. J Environ Health Sci Eng 12(1):1

Zhang H, Selim H (2005) Kinetics of arsenate adsorption-desorption in soils. Environ Sci Technol 39(16):6101-6108

Zhu J, Baig SA, Sheng T, Lou Z, Wang Z, Xu X (2015) $\mathrm{Fe}_{3} \mathrm{O}_{4}$ and $\mathrm{MnO}_{2}$ assembled on honeycomb briquette cinders (HBC) for arsenic removal from aqueous solutions. J Hazard Mater 286:220-228 